\title{
Individual Differences, Perceived Ease of Use, and Perceived Usefulness in the E-Library Usage
}

\author{
Yusliza Mohd.Yusoff (Corresponding author) \\ School of Management, Universiti Sains Malaysia \\ 11800 Minden, Penang, Malaysia
}

Tel: 6-03-5543-5847_E-mail: yusliza1977@yahoo.com

Zikri Muhammad

School of Humanities, Universiti Sains Malaysia

11800 Minden, Penang, Malaysia

E-mail: zikri69@hotmail.com

Mohd Salehuddin Mohd Zahari

Faculty of Hotel and Tourism Management

Universiti Teknologi MARA, 40450 Shah Alam, Selangor, Malaysia

E-mail: salehuddinm@yahoo.com

Ermy Syaifuddin Pasah

Faculty of Administrative Science \& Policy Studies

Universiti Teknologi MARA, 40450 Shah Alam, Selangor, Malaysia

E-mail: ermysyaifuddin@yahoo.com

Emmaliana Robert

Faculty of Administrative Science \& Policy Studies

Universiti Teknologi MARA, 40450 Shah Alam, Selangor, Malaysia

E-mail: princess_emmaliana83@yahoo.com

\begin{abstract}
This study examines the usage of e-library among students in a public university in Malaysia using the Technology Acceptance Model. Data from a questionnaire survey of 201 students were analyzed using linear regression. The results show that individual differences (computer self-efficacy and knowledge of search domain) had a significant positive relationship with perceived ease of use. Perceived ease of use showed significant relationship with perceived usefulness but non significant with the actual usage of the e-library. For perceived usefulness, it showed a significant relationship with the actual usage of the e-library. Lessons and discussions for individual differences, perceived ease of use, perceived usefulness, and actual usage are presented.
\end{abstract}

Keywords: Computer self-efficacy, Knowledge of search domain, Perceived ease of use, Perceived usefulness, Actual usage, E-library, Malaysia

\section{Introduction}

The term "e-library" has been associated with many connotations such as digital library, hybrid library, or virtual library. There are different definitions in the literature as to what constitutes an e-library. Akla (2002) as cited in Ramayah, Aafaqi, and Ignatius (2004), for example, defined e-library as the digital library that requires technology to link the resources of many libraries and information services. Deb, Kar, and Kumar (2003) defined e-library as a system that is accessible from anywhere via the Internet, to deliver knowledge directly to their users, without being confined to the contents neither of a physical library nor by being caught in a web of unorganized, unmanaged information. The emergence of e-library provides more opportunities for users to access a variety of information resources. 
There a lots of reasons why e-library is important especially for the students in doing their course work assignments, so that they can do their work more efficiently and faster. Chen (2000) pointed out that e-library use the internet to create and store massive amounts of digital media information. To satisfy the demands of library users, e-library provides highly efficient and consistent methods for the search and retrieval information. Furthermore, e-library is the integration of materials, collection, information, services and operation (Chen, 1999). Ke (2000) shows that e-library are composed of three important factors; electronic collection, electronic operation, and electronic service. Besides that, the goal of e-library is to perform online all the functions of the traditional library, plus many more available in today's digital world (Deb et al., 2003).

Millions of dollars have been invested into the development of e-library. However, research on the e-library is still in its infancy (Xie, 2006) particularly the applicability of the Theory of Acceptance Model (TAM) on user acceptance of e-library. Therefore, there is a need for research to identify the factors that determines users' adoption of e-library. Using the TAM as theoretical framework, this study investigates the effect of the set of individual differences to the usage of e-library.

\section{Review of literature and hypotheses development}

\subsection{Technology Acceptance Model (TAM)}

Davis (1986) developed the Technology Acceptance Model (TAM) in studying the determinants of IT usage. The goal of TAM was "to provide an explanation of the determination of computer acceptance that is generally capable of explaining user behaviour across a broad range of end-user computing technologies and user populations, while at the same time being both parsimonious and theoretically justified" (Davis, 1989). TAM can be seen as an adaptation of the generic Fishbein and Ajzen's Theory of Reasoned Action (TRA) and was developed to explain individual system use in the workplace (Davis, 1989). TAM posits that perceived ease of use (PEOU) and perceived usefulness (PU) are important factors that determine the user's attitude toward his or her intention to use and actual usage of information systems (IS). According to TAM, usage behavior is a direct function of behavioral intention which in turn a function of attitude toward usage reflect feelings of favorableness or unfavorableness toward using the technology and PU which reflect the belief that using the technology will enhance performance. Attitude is determined jointly by PU and PEOU (Davis, 1989). Furthermore, a key purpose of TAM is to provide a basis for discovering the impact of external variables on internal beliefs, attitudes, intentions, and usage. The TAM developed by Davis (1986) is shown in Figure 1.

\subsubsection{Individual Differences}

According to Hong, Thong, Wong, and Tam (2002), individual differences are believed to be most relevant to both IS success (Harrison \& Rainer, 1992; Zmud, 1979) and human computer interaction research (Dillon \& Watson, 1996). Individual differences play a major role in determining user performance on information retrieval systems (Chen, Czerwinski, \& Macredie, 2000). Previous studies have examined various individual differences such as computer self-efficacy (Chau, 2001; Hong et al., 2002; Ramayah \& Aafaqi, 2004; Thong, Hong, \& Tam, 2004; Ramayah, 2006; Amin, 2007; Hasan, 2006), knowledge of search domain (Hong et al., 2002; Thong et al., 2004; Ramayah, 2006), computer experience (Thong et al., 2004; Ramayah, 2006), and demographic variables (Lu, Yu, Liu, \& Yao, 2003) on technology acceptance. Following research by Hong et al. (2002), this study will examine computer self-efficacy and knowledge of search domain as individual differences in the context of e-library usage. In the following section, these individual differences will be explored that may influence user acceptance of e-library.

\subsubsection{Computer Self-Efficacy}

In the context of using IS, computer self-efficacy represents "an individual's perceptions of his or her ability to use computers in the accomplishment of task, rather than reflecting simple component skills' (Compeau \& Higgins, 1995, p. 191). Prior IS research has found that computer self-efficacy has a positive impact on perceived ease of use (Agarwal, Sambamurthy, \& Stair, 2000; Venkatesh, 2000; Hong et al., 2002; Thong et al., 2004; Hasan, 2006; Amin, 2007). The proposed relationship between computer self-efficacy and PEOU is based on the theoretical argument by Davis (1989) and Mathieson (1991). Library and information science researchers have also recognized the possible impact of computer literacy on increasing usage of information retrieval systems (Jacobson \& Fusani, 1992; Davies, 1997). Thus,

\section{$H_{1}$ : Computer self-efficacy is positively related to perceived ease of use of the e-library.}

\subsubsection{Knowledge of Search Domain}

Knowledge of search domain is another individual difference that may positively affect PEOU of e-library. According to Thong et al. (2004), in a study of information seeking behaviour in a hypertext environment, domain experts were found to conduct faster and more focused searches than did the novices (Marchionini, Lin, \& Dwiggins, 1990). Prior studies (Hong et al., 2002; Thong et al, 2004; Ramayah, 2006) have shown that knowledge of search domain does have a significant and positive relationship with PEOU. The associated hypothesis for testing in this study is as follows:

$\mathrm{H}_{2}$ : Knowledge of search domain is positively related to perceived ease of use of the e-library. 


\subsubsection{Perceived Ease of Use}

PEOU has been extensively studies in the IS literature. PEOU is the "degree to which a person believes that using a particular system would be free of effort" (Davis, 1989; Dholakia \& Dholakia, 2004). The easier it is for a user to interact with a system, the more likely he or she will find it useful (Thong et al., 2004). There is substantial empirical support for this view (Chau, 2001; Hong et al., 2002; Thong et al., 2004; Ramayah \& Aafaqi, 2004; Ramayah et al., 2004; Lallmahamood, 2007; Shim \& Viswanathan, 2007; Amin, 2007). In the digital libraries setting, Hong et al. (2002) submitted that digital libraries need to be both easy to learn and easy to use. Based on the evidence that link perceived ease of use with perceived usefulness in the context of e-library, it is hypothesized that:

$H_{3}$ : Perceived ease of use is positively related to perceived usefulness of the e-library.

When the application of the e-library is perceived to be easier to use, it is more likely to be accepted by the users. Although most researches have found perceived usefulness to be directly related to usage, there are some findings that show no significant effect on usage such as Ndubisi, Jantan, and Richardson (2001). There are also many researches that have found ease of use to be influential in system usage (Adams, Nelson \& Todd, 1992; Davis, 1989; Ramayah, Siron, Dahlan, \& Mohammad, 2002; Ramayah \& Jantan, 2004; Ramayah \& Aafaqi, 2004). Hence, the hypothesis posited in this study is as follows

\section{$H_{4}$ : Perceived ease of use is positively related to actual usage of e-library.}

\subsubsection{Perceived Usefulness}

PU is defined as "the degree to which a person believes that using a particular system would enhance his or her job performance" (Davis, 1989). Within the organizational context, a system that is high in perceived usefulness is one that the user believes will have a positive use-performance relationship. In fact, IS adoption research suggests that "a system that does not help people perform their jobs is not likely to be received favourably" (Nysveen, Pedersen, \& Thornbjomsen, 2005, p. 537). The ultimate reason that users exploit digital libraries is that they find the systems useful to their information needs or search tasks (Hong et al., 2002). Past researches (Ramayah et al., 2004; Ramayah \& Aafaqi, 2004; Davis, 1989; Mathieson, 1991; Adams et al., 1992; Segars \& Grover, 1993, Igbaria, Iivari, \& Maragahh, 1995; Igbaria, Zinatelli, Cragg, \& Cavaye, 1997; Ndubisi et al., 2001; Ramayah, Ignatius, \& Aafaqi, 2002, Ramayah, Sarkawi, \& Lam, 2003) has shown that PU influences computer usage directly. Hence, it is hypothesize that:

$H_{5}$ : Perceived usefulness is positively related to actual usage of e-library.

\section{Research model}

Based on the above discussion, an augmented TAM was proposed (Figure 2). The model was adapted from the previous study by Hong et al. (2002), Thong et al. (2004), and Ramayah et al. (2004).

\section{Methodology}

\subsection{Research design and sampling}

The population for this study was students from one of the Malaysian public university. A convenience sample was drawn from this population $(\mathrm{n}=201)$. Convenience sampling refers to the collection of information from members of the population who are conveniently available to provide it (Sekaran, 2003). A survey-questionnaire approach was used to gather data in this study. A questionnaire was personally administered to the student in the university. This method is chosen because the designed questionnaire could be collected within a short period of time and any doubts that the respondents might have on any question could be clarified on the spot (Sekaran, 2003).

The average age of the students was 23 years, and the majority (96\%) were single. More than half of the students were female (58.7\%), while 82.6 per cent were Malay, 11.9 per cent were Sarawak Bumiputera, and 5 per cent Sabah Bumiputera. In terms of status of candidacy, most students reported they are full-time students $(77.6 \%)$, the remainder part-time students. In respect of faculty, almost half of the students came from Faculty of Administrative Science and Policy Studies (43.3\%), Faculty of Information Technology and Quantitative Sciences (21.4\%), Faculty of Architecture, Planning and Surveying (2.5\%), Faculty of Mechanical Engineering (1.5\%), Faculty of Applied Sciences (3.5\%), Faculty of Hotel and Tourism Management (6.5\%), Faculty of Business Management (15.4\%), Faculty of Civil Engineering (0.5\%), Faculty of Art and Design (1\%), and Faculty of Accountancy (4.5\%).

\subsection{Measurements}

Computer self-efficacy was measured with the ten-item measure developed by Compeau and Higgins (1995). Knowledge of search domain was tapped by Davies's (1997) two-item scale. PEOU and PU were measured by four items each, taken from Hong et al. (2002). These items in the questionnaire were rated on five-point Likert scales raging from $1=$ strongly disagree o $5=$ strongly agree, except computer self-efficacy, which was rated from $1=$ not at all confident to $5=$ totally confident. Actual usage was assessed with the frequency of usage and daily usage measure developed and validated by Igbaria et al. (1995) and Thompson, Higgins, \& Howell (1991). Frequency of e-library 
usage is measured on a five-point scale ranging from $1=$ never/almost never to $5=$ several times a day, whilst daily e-library usage is measured by the amount of time spent daily on the databases. A five-point scale ranging from $1=$ never/almost never to $5=$ more than three hours per day is used to measure daily e-library usage.

\section{Findings}

\subsection{Means, standard deviations, reliability, and correlations between all study variables}

A summary of the means, standard deviations, reliability, and correlations is provided in Table 1.

It can be seen that the mean value for each of the study's variables ranges from 2.856 to 3.479 , with a standard deviation of .461 to 1.123. It revealed that all variables charted higher than the midpoints of their respective scales except for actual usage. To assess reliability among the study's variables, Cronbach's alpha values were generated. Alpha values of .765 (computer self-efficacy), 776 (knowledge of search domain), .846 (PEOU), .855 (PU), and .820 (actual usage) suggested more than adequate reliability within the respective factors (Nunnally \& Bernstein, 1994).

According to correlations between variables, PEOU and PU have a strong and positive relation $(r=.558, p<.01)$. Computer self-efficacy $(r=.243, p<.01)$ and knowledge of search domain $(r=.434, p<.01)$ affects PEOU in a positive manner, as well. However, this effect is not as strong as PU. PEOU $(r=.183, p<.01)$ and PU $(r=.224, p<.01)$ also positively affect actual usage. The zero order correlation between computer self-efficacy and PU and computer self-efficacy and actual usage were non-significant.

\subsection{Direct effects of computer self-efficacy and knowledge of search domain and perceived ease of use variables}

The results of the tests of effects of computer self-efficacy and knowledge of search domain and PEOU are presented in Table 2. It can be seen that $R^{2}$ value of .258 suggests that 25.8 per cent of the variance in the PEOU is explained by computer self-efficacy and knowledge of search domain. In addition $R^{2}$ change $(0.258)$ is significant. This implies that the additional 25.8 per cent of the variation in the PEOU is explained by knowledge of search domain and computer self-efficacy. The Durbin-Watson index (1.963) shows that auto-correlation was not the problem. Knowledge of search domain $(\beta=.459, p<.01)$ and computer self-efficacy $(\beta=.159, p<.05)$ had significant and positive effects on PEOU. Thus, $\mathrm{H}_{1}$ and $\mathrm{H}_{2}$ were supported.

\subsection{Direct effects of perceived ease of use and perceived usefulness variables}

As depicted in Table 2, the coefficient determination $\left(R^{2}\right)$ was found to be .325 indicating that 32.5 per cent of PU is explained by PEOU. The $R^{2}$ change (.325) is significant. This implies that the additional 32.5 per cent of the variation in PU is explained by PEOU. The value of Durbin Watson index is 1.883 . PEOU $(\beta=.570, p<.01)$ had significant and positive effects on PU. Based on this result, it provided support for $\mathrm{H}_{3}$.

\subsection{Direct effects perceived ease of use and perceived usefulness and actual usage variables}

An examination of Table 2 revealed that only $\mathrm{PU}(\beta=.177, p<.05)$ had significant and positive effect on actual usage. Contrary to expectation, there was no significant relationship between PEOU and actual usage. Based on these results, $\mathrm{H}_{5}$ and $\mathrm{H}_{4}$ are rejected. $R^{2}$ is 5.5 percent. The $R^{2}$ change is 5.5 per cent and was found to be significant $(p<.01)$. This findings show that an additional 5.5 percent of the variations in the actual usage is explained by PEOU and PU. The Durbin-Watson index is at 2.111, which is within the acceptable range 1.5 to 2.5 (Coakes \& Steed, 2003). It shows no auto-correlation problems detected in the model.

\section{Discussion and conclusions}

This study tested the relation between individual differences (computer self-efficacy and knowledge of search domain) and PEOU on the one hand and PEOU and PU towards the actual usage of e-library on the other. In addition, PEOU is examined in relation to PU. In general, four hypotheses were confirmed, but one was rejected.

\subsection{Computer self-efficacy}

As predicted, there was a positive relationship between computer self-efficacy and PEOU of the e-library. Thus, it received support for research hypothesis. This finding is consistent with previous research that has found positive relationship between computer self-efficacy and PEOU of use in IS research (e.g., Hong et al., 2002; Thong et al., 2004; Ramayah \& Aafaqi, 2004; Hasan, 2006; Amin, 2007). This finding implies that the high level of computer self-efficacy indicated that the students will be have high levels of confidence in using e-library in general especially in doing their assignment and more likely to find the e-library is easy to use. Hence, high level of computer self-efficacy indicates that the students will be often using e-library in their study. Besides, students can also improve their performance in their study once they are confident in using e-library.

\subsection{Knowledge of search domain}

As shown in the regression result of this study, knowledge of search domain was found to be contributing to PEOU of e-library. This result support prior research of Hong et al. (2002), Thong et al. (2004), and Ramayah (2006) on user 
acceptance of digital libraries or e-library. Domain experts could conduct faster and more focused searches than novices as they are able to separate relevant information from irrelevant responses and increase effective searches (Ramayah, 2006). This finding supports the recommendation of library science researchers to provide customized interfaces to different individuals (Archer, Head, \& Yuan, 1996; Meadow, Wang, \& Yuan, 1995). When the students are familiar and knowledgeable with e-library it will encourage the students using e-library frequently in their study.

\subsection{Perceived ease of use}

The result from this study also suggested the significant and positive relationship between PEOU and PU. This result is in line with previous studies on this link (Chau, 2001; Hong et al., 2002; Lallmahamood, 2007; Shim \& Viswanathan, 2007; Ramayah \& Aafaqi, 2004; Ramayah et al. 2004; Thong et al., 2004; Amin, 2007). This indicates that if students find that the e-library is easy to use, they will be more willing to use it for information retrieval in order to improve the quality of their assignments.

The finding of an insignificant relationship between PEOU and actual usage did concur with Ramayah and Aafaqi's (2004) and Igbaria and Iivari's (1995) insignificant finding. More work needs to be done in this area.

\subsection{Perceived usefulness}

PU was also found to be positively related to actual usage of the e-library. It implies that if students feel that a system is useful, their usage level will be higher. This finding support prior research that has found a direct positive relationship between PU and actual usage (Ramayah et al., 2004; Ramayah \& Aafaqi, 2004; Davis, 1989; Mathieson, 1991; Adams et al., 1992; Segars \& Grover, 1993, Igbaria et al., 1995, 1997; Ndubisi et al., 2001; Ramayah, Ignatius, \& Aafaqi, 2004; Ramayah, Jantan, \& Aafaqi, 2003).

\section{References}

Adams, D. A., Nelson, R. R, \& Todd, P. A. (1992). Perceived usefulness, ease of use and usage of information technology: A replication. MIS Quarterly, 6(2), 227-247.

Agarwal, R., Sambamurthy, V., \& Stair, R. M. (2000). Research report: The evolving relationship between general and specific computer self-efficacy-An empirical assessment. Information Systems Research, 11(4), 418-430.

Amin, H. (2007). Internet banking adoption among young intellectuals. Journal of Internet Banking and Commerce, 12(3), 1-13.

Archer, N. P., Head, M. M., \& Yuan, Y. (1996). Patterns in information search for decision making: The effects of information abstraction. International Journal of Human-Computer Studies, 45(5), 599-616.

Chau, P. Y. K. (2001). Influence of computer attitude and self-efficacy on IT usage behaviour. Journal of End User Computing, 13(1), 26-33.

Chen, Y. N. (1999). Another type of overview of electronic libraries: Journal of Information, Communication in Library Services, 5(3), 141-150.

Chen, C. C. (2000). Theory and practice of integrated searches at libraries. Wenhua, Taipei, 4-5.

Chen, C., Czerwinski, M., \& \& Macredie, R. (2000). Individual differences in virtual environments-Introduction and overview. Journal of the American Society for Information Sciences, 51(6), 499-507.

Coakes, S. J., \& Steed, L. G. (2003). SPSS analysis without anguish version 11 for Windows. Milton, QLD. John Wiley and Sons, Australia.

Compeau, D. R., \& Higgins, C. A. (1995). Computer self-efficacy: Development of a measure and initial test. MIS Quarterly, 19(2), 189-211.

Davis, F. D. (1986). A technology acceptance model empirical testing new end-user information systems: Theory and results. Doctoral Dissertation, Sloan School of Management, Massachucetts Institute of Technology, Cambridge, MA.

Davis, F. D. (1989). Perceived usefulness, perceived ease of use, and user acceptance of information technology, Graduate School of Business Administration. MIS Quarterly, 13(3), 319-340.

Davies, C. (1997). Organizational influences on the university electronic library. Information Processing and Management, 33(3), 377-392.

Deb, S., Kar, D. C., \& Kumar, S. (2003). Setting up electronic library: The case of TERI. Proceeding of the ASIS\&T 2003 Annual Meeting "Humanizing Information Technology: From Ideas to Bias and Back", 19-22 October, California.

Dholakia, R. R., \& Dholakia, N. (2004). Mobility and markets: Emerging outlines for m-commerce. Journal of Business Research, 57(12), 1391-1396.

Dillon, A., \& Watson, C. (1996). User analysis in HCI-The historical lessons from individual difference research. International Journal of Human-Computer Studies, 45(6), 619-637. 
Harrison, A. W., \& Rainer, R. K. (1992). The influence of individual differences on skill in end-user computing. Journal of Management Information Systems, 9(1), 93-111.

Hasan, B. (2006). Delineating the effects of general and system-specific computer self-efficacy beliefs on IS acceptance. Information \& Management, 43, 565-571.

Hong, W., Thong, J. Y. L., Wong, W. M., \& Tam, K. Y. (2002). Determination of user acceptance of digital libraries: An empirical examination of individual difference and system characteristic. Journal of Management Information System. 18(3), 97-124.

Igbaria, M., Iivari, J., \& Maragahh, H. (1995). Why do individuals use computer technology: A finnish case study. Journal of Information and Management, 29, 227-238.

Igbaria, M., Zinatelli, N., Cragg, D., \& Cavaye, A. (1997). Personal computing acceptance factors in small firms: A structural equation model. MIS Quarterly, 29(3), 278-305.

Igbaria, M., \& Iivari, J. (1995). The effect of self-efficacy on computer usage. Omega. 23(6), 587-605.

Jacobson, T., \& Fusani, D. (1992). Computer, system, and subject knowledge in novice searching of a full-text, multifile database. Library and Information Science Research, 14(1), 97-106.

Ke, H. R. (2000). Discussion of experience in establishing on electronic library: The example of National Chiao Tang University, Shu Fah Quarterly, 47, 10-33.

Koay, P. L. (2002). Receptiveness of e-banking by Malaysian consumers. Unpublished MBA Dissertation, School of Management, Universiti Sains Malaysia, Penang, Malaysia.

Lallmahamood, M. (2007). An examination of individual's perceived security and privacy of the internet in Malaysia and the influence of this on their intention to use e-commerce: Using an extension of the Technology Acceptance Model. Journal of Internet Banking and Commerce, 12(3), 1-26.

Lu, J., Yu, C. S., Liu, C., \& Yao, J. E. (2003). Technology acceptance model for wireless internet. Internet Research, 13(3), 206-222.

Marchionini, G., Dwiggins, S., Katz, A., \& Lin, X. (1993). Information seeking in full-text end-user-oriented search systems: The roles of domain and search expertise. Library and Information Sciences Research, 15(1). 35-69.

Mathieson, K. (1991). Predicting user intention: Comparing the Technology Acceptance Model with the Theory of Planned Behavior, Information Systems Research. 12(3), 173-191.

Meadow, C. T., Wang, J., \& Yuan, W. A. (1995). A study of user performance and attitude with information retrieval interfaces. Journal of the American Society for Information Science, 46(7), 490-505.

Ndubisi, N. D., Jantan, M., \& Richardson, S. (2001). Is the Technology Acceptance Model valid for entrepreneurs? Model Testing and Examining Usage Determinants. Asian Academy of Management Journal, 6(2), 31-54.

Nunnally, J. C., \& Bernstein, I. H. (1994). Psychometric theory. McGraw-Hill, New York, NY.

Nysveen, H., Pedersen, P. E., \& Thornbjomsen, H. (2005). Intentions to use mobile services: Antecedents and cross-service comparisons. Journal of Academy of Marketing Science, 33(3). 330-346.

Ramayah, T. (2006). Doing e-research with e-library: Determinants of perceived ease of use of e-library. International Journal of Technology, Knowledge and Society, 1(4), 71-82.

Ramayah, T. \& Aafaqi, B. (2004). Role of self-efficacy in e-library usage among student of a public university in Malaysia. Malaysia Journal of Library and Information Science, .9(1), 39-57.

Ramayah, T., Aafaqi, B., \& Ignatius, J. (2004a). E-library usage among students of a public university in Malaysia. The Proceedings of the International Conference on Management Education, $28^{\text {th }}-29^{\text {th }}$ June, Kuala Lumpur, Malaysia.

Ramayah, T., Ignatius, J. , \& Aafaqi, B. (2004b). PC Usage among students: The case of a private institution of higher learning. The proceedings of the International Conference on Management Education, 28-29 $9^{\text {th }}$ June, Kuala Lumpur, Malaysia.

Ramayah, T., \& Jantan, M. (2004). Internet usage among Malaysian students: The role of demographic and motivational variables. PRANJANA: The Journal of Management Awareness, 7(2), 59-70.

Ramayah, T., Jantan, M. \& Aafaqi, B. (2003). Internet usage among students of Institutions of Higher Learning: The role of motivational variables. The proceedings of the $1^{\text {st }}$ International Conference on Asian Academy of Applied Business Conference, 10-12 ${ }^{\text {th }}$ July, Sabah, Malaysia.

Ramayah, T., Siron, R., Dahlan, N., \& Mohammad, O. (2002). Technology usage among owner/managers of the SMEs: The role of demographic and motivational variables. The proceedings of The $6^{\text {th }}$ Annual Asian-Pacific Forum for Small 
Business on Small and Medium Linkages, Networking and Clustering, 16-18 ${ }^{\text {th }}$ October, Kuala Lumpur, Malaysia.

Ramayah, T., Sarkawi, F., \& Lam, S. C. (2003). Attitude and intention to use web-based supply chain management (SCM) among SMEs. The proceedings of the Asia Pacific Seminar on E-Customer Relationship Management, 8-9 ${ }^{\text {th }}$ July, Shah Alam, Selangor, Malaysia.

Sekaran, U. (2003). Research methods for business: A skill building approach. Singapore: Wiley\& Son.

Segars, A. H., \& Grover, V. (1993). Re-examining perceived ease of use and usefulness: A confirmatory factor analysis. MIS Quarterly, 17(1), 517-725.

Shim, S. J., \& \& Viswanathan, V. (2007). User assessment of personal digital assistants used in pharmaceutical detailing: System features, usefulness and ease of use. The Journal of Computer Information Systems, 48(1), 14-21.

Thompson, R. Higgins, C., \& Howell, J. (1991). Personal computing: Toward a conceptual model of utilization. MIS Quarterly, 15(1), 125-143.

Thong, J. Y. L., Hong, W., \& Tam, K. Y. (2004). What leads to user acceptance of digital libraries? Communications of the $A C M, 47(11), 79-83$.

Venkatesh, V. (2000). Determinants of perceived ease of use: Integrating control, intrinsic motivation, and emotion into the technology acceptance model. Information Systems Research, 11(4), 342-365.

Xie, H. (2006). Evaluation of digital libraries: Criteria and problems from users' perspectives. Library \& Information Science Research, 28(3), 433-452.

Zmud, R. W. (1979). Individual differences and MIS success: A review of the empirical literature. Management Science, 25(10), 966-979.

Table 1. Descriptive statistics, reliability, and correlations

\begin{tabular}{|c|c|c|c|c|c|c|c|c|}
\hline & & $\begin{array}{c}\text { Cronbach's } \\
\text { Alpha }\end{array}$ & Mean & S.D. & 1 & 2 & 3 & 4 \\
\hline 1. & $\begin{array}{l}\text { Computer } \\
\text { Self-Efficacy }\end{array}$ & .765 & 3.461 & .461 & & & & \\
\hline 2. & $\begin{array}{l}\text { Knowledge of } \\
\text { Search Domain }\end{array}$ & .776 & 3.231 & .654 & $.146^{*}$ & & & \\
\hline 3. & PEOU & .846 & 3.394 & .606 & $.243 * *$ & $.434 * *$ & & \\
\hline 4. & PU & .855 & 3.479 & .614 & .122 & $.283^{* *}$ & $.558 * *$ & \\
\hline 5 & Actual Usage & .810 & 2.856 & 1.123 & -.094 & $.236^{* *}$ & $.183 * *$ & $.224 * *$ \\
\hline
\end{tabular}

** Correlation is significant at the 0.01 level (2-tailed).

* Correlation is significant at the 0.05 level (2-tailed).

Table 2. Results of regression

\begin{tabular}{l|c|c|c}
\hline \multicolumn{1}{c|}{ Variables } & $\begin{array}{c}\text { Perceived Ease of Use } \\
\text { (Std Beta) }\end{array}$ & $\begin{array}{c}\text { Perceived Usefulness } \\
\text { (Std Beta) }\end{array}$ & $\begin{array}{c}\text { Actual Usage } \\
\text { (Std Beta) }\end{array}$ \\
\hline Computer Self-Efficacy & $.159 * *$ \\
Knowledge of Search & $.459 * * *$ & \\
Domain & & & \\
\hline PEOU & .258 & $.570 * * *$ & .085 \\
\hline PU & .258 & .325 & $.177 * *$ \\
\hline$R^{2}$ & .000 & .325 & .055 \\
$R^{2}$ Change & 1.963 & .000 & .004 \\
Sig. F Change & & 1.883 & 1.997 \\
Durbin Watson Index & & & .055 \\
\hline
\end{tabular}

Note: $* * \mathrm{p}<.05, * * * \mathrm{p}<.01$ 


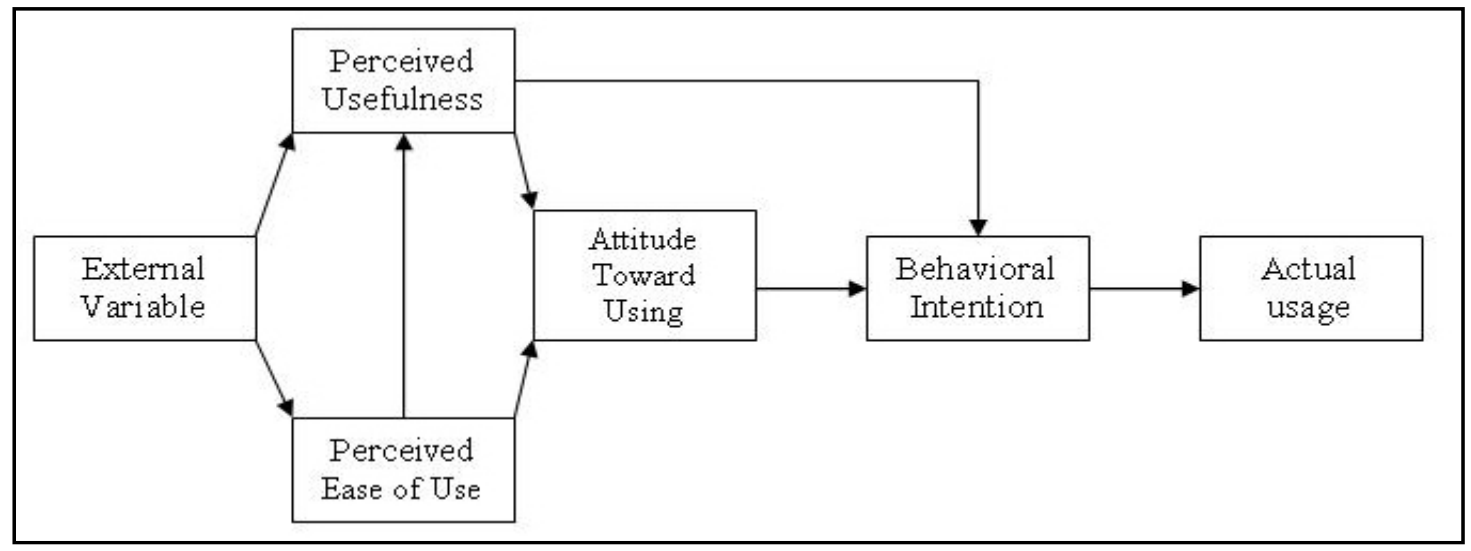

Figure 1. Technology Acceptance Model (TAM)

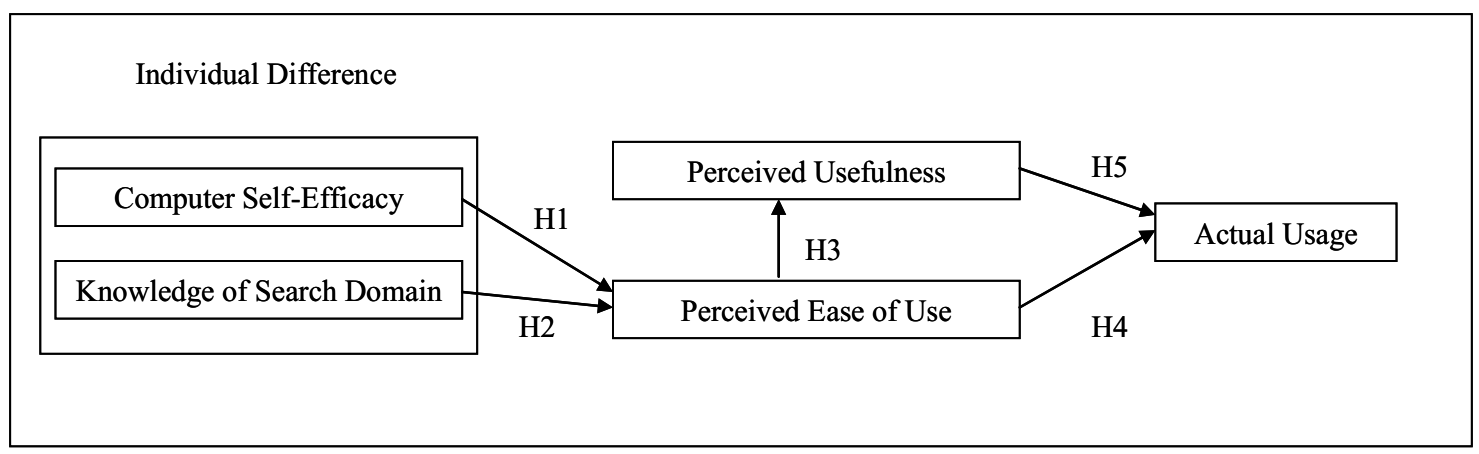

Figure 2. Research framework for e-library usage 